\title{
BMJ Open Discussing suicidality with depressed patients: an observational study in Dutch sentinel general practices
}

\author{
Elke Elzinga, ${ }^{\oplus 1}$ Renske Gilissen, ${ }^{1}$ Gé A Donker, ${ }^{2}$ Aartjan T F Beekman, ${ }^{3,4}$ \\ Derek $P$ de Beurs ${ }^{2}$
}

To cite: Elzinga $E$, Gilissen $R$, Donker GA, et al. Discussing suicidality with depressed patients: an observational study in Dutch sentinel general practices. BMJ Open 2019;9:e027624. doi:10.1136/ bmjopen-2018-027624

- Prepublication history for this paper is available online. To view these files, please visit the journal online (http://dx.doi org/10.1136/bmjopen-2018027624).

Received 31 0ctober 2018 Revised 6 February 2019 Accepted 22 February 2019

Check for updates

(C) Author(s) (or their employer(s)) 2019. Re-use permitted under CC BY-NC. No commercial re-use. See rights and permissions. Published by BMJ.

1113 Suicide Prevention, Amsterdam, The Netherlands ${ }^{2}$ Nivel, Netherlands Institute for Health Services Research, Utrecht, The Netherlands ${ }^{3}$ Psychiatry, Amsterdam Public Health (research institute), Amsterdam UMC, Vrije Universiteit Amsterdam, Amsterdam, The Netherlands ${ }^{4} \mathrm{GGZ}$ inGeest Specialized Menta Health Care, Amsterdam, The Netherlands

Correspondence to

Elke Elzinga; e.elzinga@113.nl

\section{ABSTRACT}

Objectives This paper aims to describe the degree to which general practitioners (GPs) explore suicidal behaviour among depressed patients in the Netherlands. Design An observational study of consultations between GPs and depressed patients.

Setting 39 sentinel GP practices within the Netherlands in 2017.

Participants Patients with a registration of depression. Primary and secondary outcome measures Primary outcome measure is suicide exploration by the GP. Secondary outcome measures at patient level, assessed by surveying GPs, include prevalence and severity of suicidal thoughts. Secondary outcome measures at GP level include follow-up actions of GP and reasons not to explore suicidality.

Results A total of 1034 questionnaires were included in the analyses. GPs assessed and explored suicidality in $44 \%$ of patients with depression $(66 \%$ in patients with a new episode of depression). GPs explored suicidal feelings more often in patients with a new episode of depression (OR 4.027, $\mathrm{p}<0.001,95 \% \mathrm{Cl} 2.924$ to 5.588), male patients (OR 1.709, $\mathrm{p}<0.001,95 \% \mathrm{Cl} 1.256$ to 2.330 ) or younger patients (OR 1.017, $\mathrm{p}<0.001,95 \% \mathrm{Cl} 1.009$ to 1.026 ). Multilevel analysis showed that $22 \%$ of the variation in suicide exploration is due to differences in GP practice. Thirty-eight per cent of the patients who were asked by their GP, reported (severe) suicidal ideation. Most GPs $(68 \%)$ did not explore suicidal feelings because they thought the patient would not be suicidal.

Conclusion GPs explored suicidal thoughts in less than half of all depressed patients and in two-thirds of patients with a new episode of depression. Suicide prevention training is recommended to enhance suicide exploration.

\section{INTRODUCTION}

Globally, almost 800000 people die as a result of suicide every year and many more attempt suicide. ${ }^{1}$ The global average suicide rate is 10.6 per 100000 inhabitants. ${ }^{2}$ Both Europe and the Netherlands exceed this global average with respectively 15.4 and 12.6 per 100000 inhabitants. $^{2}$ In the Netherlands, 1917 people died as a result of suicide in 2017..$^{3}$ In addition, it was estimated that 310000 Dutch people make a suicide attempt

\section{Strengths and limitations of this study}

- First Dutch study on suicide exploration by general practitioners (GPs) in depressed patients.

- GPs completed questionnaires straight after their consultation, limiting the chance on recall bias or overestimation of suicide exploration rates.

- A large dataset was collected including information on 1034 consultations.

- The prevalence of suicidal ideation among patients who were not asked about suicidal feelings is unknown, as well as whether GPs made a correct assessment not to discuss suicidality with these patients.

- This study largely depends on the labelling practices of the GPs: consultations with depressive patients who were not labelled as such are not included in this study.

and 1.3 million experience suicidal thoughts once in their life. ${ }^{4}$

General practitioners (GPs) play a central role in the recognition and management of patients with suicidal ideation. In many countries, GPs are patients' first point of contact with the healthcare system and therefore capable of signalling suicidal ideation at an early stage. Once recognised, they also function as a gatekeeper to more specialised care. GPs can either decide to treat a patient in primary care or refer the patient to mental healthcare services. ${ }^{5}$ Since early identification and treatment of suicidal ideation may prevent suicidal behaviour, ${ }^{6}$ GPs are the focus of many suicide prevention strategies. ${ }^{78}$

Many persons are in contact with the healthcare system prior to their suicide or suicide attempt. ${ }^{9-15}$ An international review showed that patients were more likely to contact primary care services than mental health services: approximately one-fifth of patients were in contact with mental health services and half of the patients were in contact with primary care services within 1 month of their suicide. ${ }^{10}$ Another study reported that about 
one-third of patients are in contact with primary care services alone. ${ }^{9}$ In the Netherlands, $42 \%$ of patients who died as a result of suicide was treated by mental health services ${ }^{16}$ and $48 \%$ was in contact with primary care services prior to fatal or near-fatal suicidal behaviour. ${ }^{11}$

Even though contact with primary care services prior to suicide or suicide attempt is common, recognition of suicidal ideation remains difficult. Pearson $e t a l^{14}$ found that $27 \%$ of GPs were concerned for their patients safety prior to their suicide and Dutch GPs identified patients' imminent risk for suicide in only $31 \%$ of patients who later engaged in fatal or near-fatal suicidal behaviour. ${ }^{11}$ There can be different reasons why these recognition rates are low: risk factors may not be distinctive enough and GPs might avoid discussing suicidal ideation with patients as they find it a difficult topic to address. ${ }^{17}$

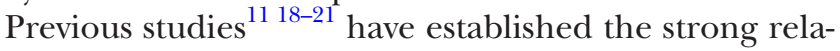
tion between suicide and depression. Assessing suicidal ideation in patients with depression may be worthwhile: where suicidal ideation in the general primary care population is estimated at $1 \%-10 \%,{ }^{17}$ among depressed patients it is considerably higher $(54 \%) .{ }^{21}$ Various international clinical guidelines for depression or suicide prevention, ${ }^{62-24}$ therefore, recommend to screen and monitor suicide risk in all patients diagnosed with depression.

A previous French study ${ }^{25}$ reported that $86 \%$ of GPs explore suicide risk often or very often among patients with depression. A British study ${ }^{26}$ described that nearly all (92\%) GPs reported that they sometimes screened for suicidal ideation, especially when patients showed symptoms of depression. A study using standardised patients simulating major depression, ${ }^{27}$ reported suicide exploration rates of $42 \%$. Another French study ${ }^{28}$ reported that GPs successfully identified suicidal ideation in 52\% of patients who started antidepressant or anxiolytic treatment. However, accurate measures of GPs' suicide exploration rates in depressed patients are lacking.

This observational study in Dutch sentinel practices aims to describe the degree to which GPs explore suicidal behaviour among depressed patients, using an automatically triggered questionnaire implemented in the GP information system of the sentinel practices. This method will likely limit recall bias and provide a more realistic representation of GPs' suicide exploration compared with previous studies. It is hypothesised that suicidal feelings are more often assessed in patients diagnosed with a new episode of depression, since it is an indication of the severity of depression. ${ }^{29}$ Furthermore, since male gender and older age indicate a higher risk on death by suicide, ${ }^{3} 30$ suicide exploration may be more common among these patients.

\section{METHODS}

\section{Population and setting}

This study included the Dutch sentinel GP practices, a nationally representative subgroup of practices within the Nivel Primary Care database. Sentinel GPs register and report information on the occurrence of various illnesses, incidents and interventions in the general practice that cannot be derived from automated registrations. For some illnesses, additional data are obtained by prompting electronic questionnaires to the GPs using an application which is implemented in the GP information system.

The sentinel network is in place since 1970 and currently consists of 72 GPs working in 39 different GP practices throughout the country. The practices have a total of 139094 registered patients, which account for approximately $0.8 \%$ of the Dutch population. Patients are representative for the population in gender, age, geographical distribution and population density. ${ }^{31}$

\section{Procedure and questionnaire}

In 2017, a specific depression module and questionnaire were implemented in the GP information system of the sentinel practices. Patients with depressive disorder were selected using the International Classification of Primary Care (ICPC) code 'depressive disorder (P76)'. When GPs updated the electronic medical records of these patients, the module prompted questions to verify that it concerned a face-to-face encounter with a depressed patient. After confirming these questions, the GPs were directed to the 'Suicide Prevention within Primary CareScale', a questionnaire designed by Gilissen $e t$ al for the purpose of this study. The questionnaire was based on recommendations from the Dutch suicide prevention guideline $^{6}$ and experts from the field. It assessed whether or not GPs had explored suicidal thoughts, the intensity of the thoughts and concreteness of suicidal plans. Furthermore, the questions focused on the actions or interventions that GPs agreed on with patients reporting suicidal thoughts. ${ }^{8}$ Completed questionnaires were automatically sent to a database at Nivel.

\section{Patient and public involvement}

Patients were not involved in determining the design, the recruitment to or conduct of the study. GPs were involved in these processes, as the protocol was discussed in the sentinel practices advice committee with sentinel GP participation and with the sentinel GPs on their annual meeting before the start of the project. During that meeting, they could provide feedback, ask questions or object the proposal. Results of the study will be disseminated to the GPs by means of a plenary presentation and a report.

\section{Statistical analyses}

From 1 January to 31 December 2017, GPs completed questionnaires regarding consultations with patients diagnosed with depression. Descriptive statistics were used for patients' characteristics and the prevalence of suicide exploration and suicidal feelings. Multilevel multiple logistic regression was applied to determine whether age, gender and new episodes of depressive disorder were related to the primary outcome measure (GPs' suicide exploration) or patients' suicidal ideation. To control for 
the influence of GP practice a random intercept for GP practice was added to the model. Multilevel analyses were done using the $\mathrm{R}$ package lme $4 .{ }^{32}$ The intraclass correlation coefficient (ICC) was calculated at practice level to estimate variation between practices using the $\mathrm{R}$ package sjstats. $^{33}$

$\chi^{2}$ tests were carried out to test for significant differences between patients with new and existing episodes. A new variable was computed to indicate the severity of suicidality. This variable was created from items assessing patients' frequency of suicidal thoughts, perceived control over these thoughts and actual preparation of an attempt. ${ }^{34}$ In addition, items assessing patients' rumination, hopelessness, entrapment and burdensomeness were added. ${ }^{35}$ Adding up these items created a 'sum score of suicidality' ranging from 0 to 7 , with 0 referring to the least and 7 to the most severe suicidal. A multiple linear regression model was used to study the influence of age, gender, episode of depression (new vs existing) and the interaction terms of these variables on the severity of suicidality.

The item 'follow-up actions' was recoded into a mutually exclusive ordinal variable. 'Adopted a wait and see policy', 'recommended online tools' and 'made the patient aware of suicide crisis hotline' were all recoded into 1. Made a follow-up appointment was recoded 2. Referring the patient to either a mental health nurse, basic or specialised mental healthcare were recoded into respectively 3, 4 and 5. Consulting the crisis services or an affiliated psychiatrist was recoded as 6 . When multiple actions were carried out, only the strongest one counted. Thus, whenever a GP selected both 'made the patient aware of suicide crisis hotline (1)' and 'made a follow-up appointment (2)', only the latter counted. A Spearman's rank-order correlation test was performed to study the association between severity of suicidality and follow-up actions of the GP. 'Prescribed antidepressants' and 'other' were excluded for the test, because of too many missing values (antidepressants) and the open field (other). For these variables, numbers and percentages are described.
Statistical tests were carried out two sided and $\mathrm{p}$ values below 0.05 indicated statistical significance. Descriptive analyses and $\chi^{2}$ tests were carried out with SPSS V.25.0. Multilevel analyses were done using the R statistical software environment. ${ }^{36}$

\section{RESULTS}

During 2017, the sentinel GPs registered 1104 consultations with patients with depression. They completed questionnaires concerning $1081(98 \%)$ of these consultations. Of these, $37(3.4 \%)$ were excluded because they did not refer to a face-to-face encounter between the GP and the patient. The remaining 1034 questionnaires were included in the analyses. The mean number of completed questionnaires per practice was 26.5, varying from 2 to 119 completed questionnaires per practice. GPs reported that one-third of the patients (342) presented with a new episode of depressive disorder during the consultation, the other $692(66.9 \%)$ patients had an existing episode. Two-thirds (666 or $64.4 \%$ ) of the encounters concerned female patients and one-third (368 or $35.6 \%$ ) males. The mean age of the patients was 49.4 years (SD 18.3) at time of the consultation, with ages varying between 14 and 97 years old.

\section{Suicide exploration by GPS}

During the consultation, GPs explored suicidal feelings in $455(44 \%)$ of all 1034 depressed patients and in 225/342 $(66 \%)$ patients with a new episode (table 1). Multilevel analysis indicated that GPs explored suicidal feelings more often in patients presenting a new episode of depression (OR 4.027, $\mathrm{p}<0.001,95 \%$ CI 2.924 to 5.588) or male patients (OR 1.709, p<0.001, 95\% CI 1.256 to 2.330 ). Every year a patient was younger, the OR of being asked about suicidal feelings increased with $1.017(\mathrm{p}<0.001,95 \%$ CI 1.009 to 1.026$)$. The proportion of variance explained by general practice (the ICC) was $22 \%$. The proportion of encounters during which GPs explored suicidal ideation at the 25th and 75th percentiles are, respectively, $24.4 \%$

Table 1 Characteristics of patients in who suicidality was and was not explored $(n=1034)$

\begin{tabular}{llll}
\hline & $\begin{array}{l}\text { Suicidality explored } \\
\text { N (\%†) }\end{array}$ & $\begin{array}{l}\text { Suicidality not explored } \\
\text { N (\%†) }\end{array}$ & $\begin{array}{l}\text { Total } \\
\text { N (\%) }\end{array}$ \\
\hline $\begin{array}{l}\text { Gender* } \\
\text { Male }\end{array}$ & $188(51.1)$ & $180(48.9)$ & $368(100)$ \\
$\quad$ Female & $267(40.1)$ & $399(59.9)$ & $666(100)$ \\
Mean age (SD)* & $46.4(18.5)$ & $51.8(17.8)$ & $49.4(18.3)$ \\
Episode of depression & & & $692(100)$ \\
$\quad$ Existing & $230(33.2)$ & $462(66.7)$ & $342(100)$ \\
$\quad$ New & $225(65.8)$ & $117(34.2)$ & $1034(100)$ \\
\hline Total & $455(44)$ & $579(56)$ & \\
\hline
\end{tabular}

*Significant at level $p<0.001$.

†Percentages are presented for the row and add up to $100 \%$ horizontally. 
Table 2 Reasons provided by GPs not to explore suicidal feelings among patients with depressive disorder ( $\mathrm{n}=579$ )

\begin{tabular}{|c|c|c|c|}
\hline & $\begin{array}{l}\text { New episode } \\
\mathrm{N}(\% \dagger)\end{array}$ & $\begin{array}{l}\text { Existing episode } \\
\mathrm{N}(\%+)\end{array}$ & $\begin{array}{l}\text { Total } \\
\text { N (\%†) }\end{array}$ \\
\hline I thought the patient would not be suicidal ${ }^{*}$ & $97(82.9)$ & $294(63.6)$ & $391(67.5)$ \\
\hline The patient indicated earlier that he/she was not suicidal ${ }^{\star *}$ & $13(11.1)$ & $115(24.9)$ & $128(22.1)$ \\
\hline There was not enough rapport to ask such a sensitive question & $3(2.6)$ & $10(2.2)$ & $13(2.2)$ \\
\hline I did not want to give the patient any ideas & $1(0.9)$ & $1(0.2)$ & $2(0.3)$ \\
\hline Other & $17(14.5)$ & $99(21.4)$ & $116(20)$ \\
\hline Total no of GPs & 117 & 462 & 579 \\
\hline Total no of responses & 131 & 519 & 650 \\
\hline
\end{tabular}

Significant at level ${ }^{*} \mathrm{p}<0.001,{ }^{* *} \mathrm{p}=0.001$.

†Percentages are presented for the number of GPs and do not add up to $100 \%$ due to multiple response item.

GPs, general practitioners.

and $51.3 \%$. For patients with a new episode of depression, these proportions are, respectively, $39.2 \%$ and $69.2 \%$.

Reasons not to explore suicidal feelings are presented in table 2. The most frequent reported reason overall was 'I thought the patient would not be suicidal' (67.5\%). This reason was more often reported for patients with a new episode $(82.9 \%)$ than patients with an existing episode of depressive disorder $(63.6 \%), \chi^{2}(1)=15.809$, $\mathrm{p}<0.001$. 'The patient indicated earlier that he or she was not suicidal' was more often reported for patients with an existing episode $(24.9 \%)$ than a new episode $(11.1 \%)$, $\chi^{2}(1)=10.296, p=0.001$. A small minority of GPs $(2.2 \%)$ reported that there was not enough rapport to ask such a sensitive question. Two GPs did not explore suicidal thoughts in one occasion $(0.3 \%)$, because they did not want to give the patient any ideas. The GPs selected the option 'other' 116 times (20\%), mostly because of comorbidity, for instance, due to dementia or a threatening psychosis, or when patients were referred to or under treatment of another healthcare professional. Starting or adapting medication was another frequently mentioned reason not to explore suicidal thoughts. Time constraints and cultural issues were reported only twice.

\section{Prevalence and severity of suicidal feelings}

GPs described that $174(38.2 \%)$ of the 455 patients in whom they explored suicidality, reported suicidal feelings (see table 3). Forty-seven (10.3\%) indicated they experienced suicidal feelings multiple times a day and $127(27.9 \%)$ experienced these several times a week. The remaining 281 patients $(61.8 \%)$ did not report suicidal feelings to their GP. Multilevel multiple logistic regression was performed to check whether gender, age and episode of depression were significantly associated with having suicidal feelings (yes/no). When controlling for practitioner, no independent variable was significantly related to having suicidal feelings. The proportion of variance explained by general practice (ICC) was $24 \%$.

A large majority of the 174 suicidal patients ruminated $(81.6 \%)$, experienced hopelessness $(64.9 \%)$, felt entrapped (55.7\%) and felt like a burden to others (42\%, table 4). Whether a patient had concrete plans of taking their life was inquired most often by the GPs (97.7\%). Almost a quarter $(22.4 \%)$ of the patients reported that they had a concrete plan to take their life and $23(13.2 \%)$ reported that they did not trust themselves. $\chi^{2}$ tests were

\begin{tabular}{lllll}
\hline $\begin{array}{l}\text { Table } 3 \\
\text { explored) }(n=455)\end{array}$ & $\begin{array}{l}\text { Characteristics of patients with and without suicidal feelings (measured among patients in whom suicidality was } \\
\text { Multiple times a day } \\
\text { N (\%*) }\end{array}$ & $\begin{array}{l}\text { Several times a week } \\
\mathbf{N}\left(\%^{*}\right)\end{array}$ & $\begin{array}{l}\text { No suicidal feelings } \\
\mathbf{N}\left(\%^{*}\right)\end{array}$ & $\begin{array}{l}\text { Total } \\
\mathbf{N}(\%)\end{array}$ \\
\hline $\begin{array}{l}\text { Gender } \\
\text { Female }\end{array}$ & $23(8.6)$ & $75(28.1)$ & $169(63.3)$ & $267(100)$ \\
$\quad$ Male & $24(12.8)$ & $52(27.7)$ & $112(59.6)$ & $188(100)$ \\
Mean age (SD) & $42.5(19.1)$ & $44.1(19.3)$ & $48.1(17.8)$ & $46.4(18.5)$ \\
Episode of depression & & & & \\
$\quad$ New & $23(10.2)$ & $70(31.1)$ & $132(58.7)$ & $225(100)$ \\
Existing & $24(10.4)$ & $57(24.8)$ & $149(64.8)$ & $230(100)$ \\
Total & $47(10.3)$ & $127(27.9)$ & $281(61.8)$ & $455(100)$
\end{tabular}

*Percentages are presented for the row and add up to $100 \%$ horizontally. 
Table 4 Prevalence of suicide-related risk factors among patients experiencing suicidal feelings $(n=174)$

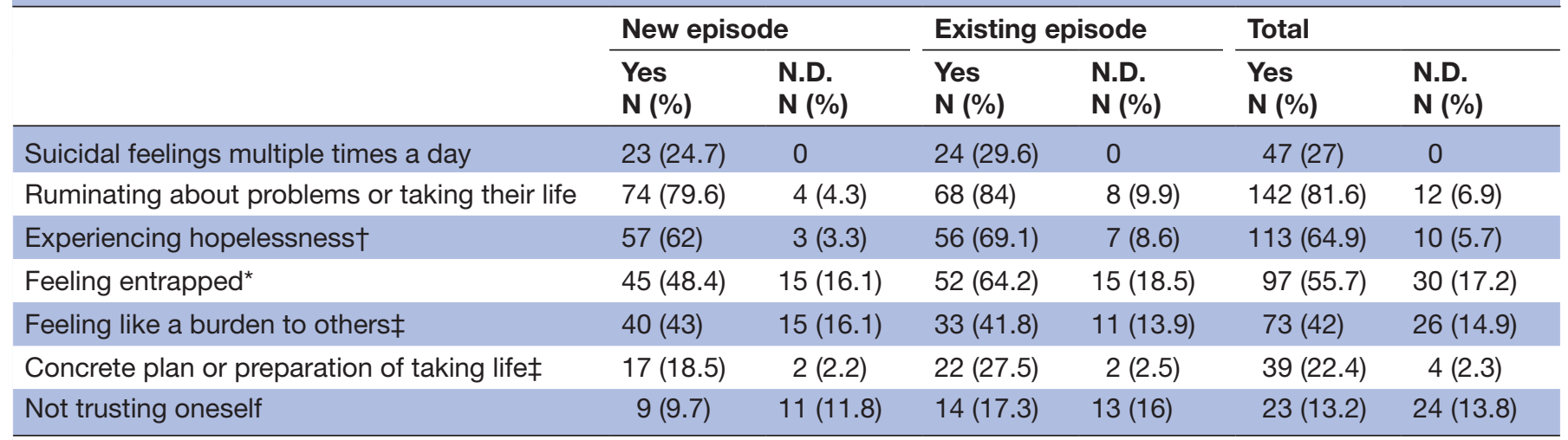

*Significant at level $\mathrm{p}<0.05$.

†Missing $n=1$.

łmissing $\mathrm{n}=2$.

N.D., not discussed.

carried out to test for differences between prevalence of these factors in patients with new or existing episodes of depression. Only 'feeling entrapped' differed significantly between the two groups $\chi^{2}(1)=7.394, p=0.025$. Patients with an existing episode more often felt entrapped $(64.2 \%)$ compared with patients with a new episode $(48.4 \%)$.

The sum score of suicidality is an indication of the patient's severity of suicidality. It was calculated by adding up the risk factors from table 4 . The mean sum score of all patients was 3 (SD 1.6, range: 0-7). No significant differences were found with regard to sum score of suicidality between patients with new $(\mathrm{M}=2.85, \mathrm{SD}=1.615)$ and existing $(\mathrm{M}=3.32, \mathrm{SD}=1.619)$ episodes of depressive disorder $\left(\chi^{2}(7)=7.238, \mathrm{p}=0.405\right)$. Most patients experienced $4(25.3 \%)$ or $3(20.7 \%)$ symptoms simultaneously. Multiple linear regression techniques showed no influence of age, gender and episode of depressive disorder on severity of suicidality $(\mathrm{F}(3,170)=1.246, \mathrm{p}=0.295)$.

\section{Follow-up actions of GPs}

GPs registered the presence of suicidality in $91.9 \%$ of the 174 patients who reported suicidal feelings. Most GPs
(70.7\%) registered this in an open field of the patient's electronic medical record. Another 19.1\% registered the presence of suicidality in the referral to a mental healthcare specialist. In $8.1 \%$ of the encounters the presence of suicidality was not registered. Significant others were involved in most suicidal patients $(71.8 \%)$, either by the GPs directly $(32 \%)$ or by discussing with patients how to involve them $(68.6 \%)$.

Follow-up actions included mostly a referral to specialised mental healthcare $(31.7 \%)$ or the mental health nurse $(20.1 \%)$. Further actions included inviting a patient for a follow-up appointment with the GP $(18.9 \%)$, consulting the crisis service or a liaison psychiatrist $(16.5 \%)$ or referring the patient to basic mental healthcare $(12.8 \%)$ (see table 5). In some cases, GPs adopted a wait and see policy $(2.9 \%)$ or pointed out the suicide crisis hotline $(2.3 \%)$, but always in addition to one of the other stronger measures, hence these are not in the table. Spearman's rank-order correlation test showed that there was a weak but significant correlation between severity of suicidality and follow-up actions from table $5(\rho=0.281 ; p<0.001$; $\mathrm{n}=164)$. From the 106 patients $(64.6 \%)$ who were referred

Table 5 Follow-up actions carried out by the GP for patients reporting suicidal feelings (multiple answers were possible, but only the strongest measure is presented here) $(n=164)$

\begin{tabular}{lllc}
\hline & $\begin{array}{l}\text { New episode } \\
\text { N (\%*) }\end{array}$ & $\begin{array}{l}\text { Existing episode } \\
\mathbf{N ~ ( \% * )}\end{array}$ & $\begin{array}{c}\text { Total } \\
\mathbf{N}\left(\%^{*}\right)\end{array}$ \\
\hline Made a follow-up appointment & $16(17.8)$ & $15(20.3)$ & $31(18.9)$ \\
Patient referred to mental health nurse & $19(21.1)$ & $14(18.9)$ & $33(20.1)$ \\
Patient referred to basic mental healthcare & $17(18.9)$ & $4(5.4)$ & $21(12.8)$ \\
Patient referred to specialised mental healthcare & $26(28.9)$ & $26(35.1)$ & $52(31.7)$ \\
Consulted crisis services or a liaison psychiatrist & $12(13.3)$ & $15(20.3)$ & $27(16.5)$ \\
Total & $90(100)$ & $74(100)$ & $164 \dagger(100)$ \\
\hline
\end{tabular}

${ }^{*}$ Percentages are presented for the column and add up to $100 \%$ vertically.

†Missing $n=10$.

GP, general practitioner. 
to another healthcare professional, the GP checked in 86 cases $(81.1 \%)$ whether patients followed up on these appointments. Antidepressants were prescribed to 59 out of 100 patients. GPs also provided other follow-up actions $(\mathrm{n}=24,13.8 \%)$, which included, for example, referral to district team, artistic therapy or sleeping medication.

\section{DISCUSSION}

\section{Suicide exploration rates by GPS}

Most guidelines ${ }^{62-24}$ encourage GPs to explore suicidal feelings among patients who are suffering from major depressive disorder. Our study suggests that GPs explore suicidal feelings in around half of the face-to-face consultations with depressed patients. As hypothesised, patients presenting a new episode of depression had higher odds of being asked about suicidal feelings than patients with an existing episode. GPs explored suicidal feelings in two-thirds of patients with a new episode of depression and in one-third of patients with an existing episode. We also expected that suicidal feelings would be more often explored in males and older patients, because of their increased risk on engaging in fatal suicidal behaviour. ${ }^{3}$ Males were indeed associated with higher exploration rates, but older age was not. Strikingly, younger patients were more often questioned about suicidal ideation.

There was large variation between GP practices with regard to suicide exploration; 22\% of the variation in suicide exploration is due to differences in GP practice. GPs in the lowest quartile only asked for suicidal ideation in up to a quarter of the depressed patients. We lack data to further explore the origins of practice variation, but it is very unlikely that casemix differences of the patients can explain this variation. Bocquier $e t a l^{25}$ showed that French GPs also vary in exploring suicidal ideation among depressed patients. Their variability was partly explained by GP-related factors: GPs' age $(<50)$, personal history with psychotherapy, continuing medical education on suicide, participation in a formal mental health network and experience with patients completed or attempted suicide in the past 5 years all added significantly to their likelihood of exploring suicidal feelings. Perceived barriers that were associated with lower suicide exploration scores include lack of training, reluctance to ask about suicide, lack of skills and lack of time. ${ }^{25}$ An earlier study ${ }^{27}$ showed that GPs working in a non-academic setting explore suicidality less often, whereas personal experience with depression resulted in more frequent suicide exploration. Furthermore, they reported significant physician variance of $57 \%$ which could not be attributed to physician specialty (family medicine or internal medicine), sex, communication style or perceived barriers to or confidence in treating depression. More research is needed to study the role of these and other unspecified factors more thoroughly. Possibly, educational programmes aiming at suicide prevention may decrease the variability between GPs and result in a more unequivocal approach towards suicide exploration.
Bajaj $e t a t^{26}$ found that most common barriers to screen for suicidal ideation included insufficient time and cultural issues. In addition, they found that a quarter of the GPs believed that screening for suicidality could induce or trigger such behaviour or thoughts. In the current study, time or cultural reasons were only mentioned twice. Furthermore, two GPs reported in one occasion that they did not explore suicidality because they feared it might trigger suicidality. A recent meta-analysis showed that assessing suicidality does not induce suicidality. ${ }^{37}$ One study even reported a decrease in suicidal thoughts and stress symptoms after exposure to questions about suicidal behaviour. ${ }^{38}$ Fear for negative effects of talking about suicidality should thus no longer be a reason to avoid this.

The most common reason GPs mentioned for not exploring suicidal thoughts among our sample of depressed patients, included that they thought the patient would not be suicidal, rendering talking about suicidality not necessary. This is worrying, because it implies that these GPs relied on assumptions. While previous studies ${ }^{1114}$ have shown that GPs were concerned for less than one-third of patients who later engaged in serious suicidal behaviour, indicating that these assumptions are not fool proof. In addition, patients tend to avoid the issue of suicidality if not initiated by the physician. ${ }^{39}$ The high a priori chance of depressed patients endorsing suicidality when asked $(38 \%)$ stresses the importance of exploring suicidality in these patients. Some GPs reported that they did not explore suicidal feelings because the patient had already indicated not being suicidal in an earlier consultation. It appears that these GPs may not be aware of the transient nature of thoughts about suicide and the importance of regularly assessing feelings about suicide in those deemed to be at some level of risk.

\section{Prevalence and severity of suicidality among patients}

Primary care data on suicidal ideation are scarce. Many studies $^{11} 141920$ describe the high prevalence of psychiatric disorders, among which depressive disorder, after a patients' suicide or attempted suicide. However, few studies have described the rate of suicidal thoughts among depressed patients in primary care. The current paper reports that of the depressed patients who were asked about it, $38 \%$ reported feeling suicidal in the past week, of which a quarter was experiencing suicidal feelings multiple times a day.

GPs are recommended to assess the presence and the severity of suicidal ideation in patients with depression. This includes assessing whether patients have a specific plan, intention to harm oneself, reasons for living and impulse control. ${ }^{56}$ We found that most GPs, when identifying suicidality, made further assessments as to the severity. The question most often asked was whether patients had a concrete plan of ending their life, which almost a quarter had. This indicates that some of these primary care patients were severely suicidal. More research 
is needed to study whether patients whose suicidality was not explored show similar rates and severity of suicidality.

\section{Follow-up actions of GPs}

Once a patients' suicidality had been established, most GPs registered this finding. Two-thirds of suicidal patients were referred to a mental healthcare specialist and most were checked on arrival by their GP. There was a weak correlation between severity of suicidality and follow-up actions, indicating that the follow-up response increased with the severity of a patient's suicidality. The high level of referral to specialised mental healthcare and the care taken to make sure patients arrive in mental healthcare shows that, for GPs, suicidality is a symptom that requires specialist attention. It may be at odds with the multidisciplinary guideline for suicide prevention, ${ }^{6}$ which states that primary care patients with mild to moderate suicidal ideation can be effectively treated in primary care setting. Past studies have described similar referral rates for suicidal patients. Marquet $e t a t^{20}$ reported referral rates of $63 \%-65 \%$ to mental healthcare professionals and Pearson et $a l^{14}$ found that $64 \%$ of GPs contacted mental health services, either to discuss or to refer patients.

\section{Recommendations}

In line with most existing guidelines, our data suggest that it is wise and worthwhile to actively explore suicidality in all patients treated for depression in primary care. Avoiding this may rest on the assumption that patients communicate their suicidal intent when present. However, previous work ${ }^{39}$ suggests that professionals and patients tend to avoid the issue of suicidality if not actively approached. Suicidal feelings are often transient in nature. They are not necessarily present during diagnosis of a (new episode of) depressive disorder, but may develop in a later stadium. Therefore, it is important to assess and reassess suicidality regularly in these patients. Since almost half of the people engaging in serious suicidal behaviour visit their GP in the month preceding the event, ${ }^{11}$ every consultation might pose an opportunity to prevent a patient from acting on their feelings.

Suicide prevention training for GPs, during which the importance for consequent and frequent exploration of suicidal feelings is stressed, is recommended. Training may have a positive effect on screening capabilities of GPs and it may result in improved care for suicidal patients. Various population-scale studies have shown a reduction in suicidal behaviour shortly after such training programmes were incorporated. ${ }^{7194041}$ A suggestion for future studies is to include GP-related factors such as personal or professional experience with mental health problems, age and being part of a formal health network, ${ }^{25} 27$ to help explain the practice variation.

\section{Limitations}

This study has some limitations. The most important one is that it remains uncertain to what extent GPs who did not explore suicidal feelings thinking their patients were not suicidal, made a correct assessment. To rule out that similar prevalence of suicidal feelings will be found in these patients, future studies should validate these GPs assessments by assessing the suicidal status of all depressed patients in primary care. The authors are currently designing a study in which this will be addressed. Patients who are diagnosed with a depression or depressed feelings will be invited to participate in a survey assessing among others their suicidal ideation.

In addition, GPs may have had justifiable reasons not to ask for suicidality. A GP generally has much more information about their patients than the variables measured in this study. Factors, such as physical or psychological comorbidity, marital status and social environment, are associated with an increased suicide risk ${ }^{6542}$ and possibly play a role in a GP's decision to explore suicidal thoughts. Nevertheless, we cannot reveal the influence of these factors on the exploration rates in this study. In addition, the suicide exploration rate of the GPs is possibly overestimated. The questionnaire itself may have had a strong learning effect and encouraged GPs to ask for suicidal thoughts more often than they would normally do. Furthermore, because it is a self-reported questionnaire, some GPs may have given socially desirable answers.

Another important limitation is that this study largely depended on the labelling practices of the GPs and these practices likely vary among GPs as well. A study ${ }^{43}$ reported that although most GPs recognise their patients as depressed, they only labelled about one-third as such. The current study represents only patients who were registered with a depressive disorder.

\section{CONCLUSION}

This exploratory study of GP consultations showed that GPs explore suicidal feelings in almost half of their depressed patients and in two-thirds of patients with a new episode. It also showed there was large variation between practices. GPs described that patients in whom they have explored suicidal feelings, reported high rates $(38 \%)$ of suicidal feelings, of which almost a quarter had concrete plans of ending their life. More research is needed to study whether similar rates will be found among patients whose suicidality was not explored. Previous studies have shown positive effects of suicide prevention training on the recognition of suicidal behaviour. Therefore, we recommend suicide prevention training for GPs and incorporation of these themes into the GP training curriculum.

Acknowledgements We thank all sentinel GPs from Nivel Primary Care database for participating in the study and completing the questionnaires.

Contributors DPdB and GAD designed the study and the GP questionnaire, instructed the GPs and prepared the data for analysis. EE performed the data analysis and drafted the manuscript. DPdB checked the data analysis. DPdB, $\mathrm{RG}, \mathrm{ATFB}$ and GAD made critical revisions and edited the manuscript. All authors contributed to and approved the final manuscript.

Funding This work was supported by the Ministry of Health grant number (326961, 2017).

Competing interests None declared. 


\section{Patient consent for publication Not required.}

Ethics approval Patients were never directly assessed by the researchers, as patient's characteristics were obtained by surveying GPs. In addition, the dataset did not include personal identifiers from patients nor GPs. According to European legislation, neither obtaining informed consent from patients nor approval by a medical ethics committee is obligatory for this type of observational studies containing no directly identifiable data. The study design was discussed and approved in the Sentinel Practices and Surveillance Advisory Board Meeting of 11 October 2016, NZR064-111016 (meeting report).

Provenance and peer review Not commissioned; externally peer reviewed. Data sharing statement № additional data are available.

Open access This is an open access article distributed in accordance with the Creative Commons Attribution Non Commercial (CC BY-NC 4.0) license, which permits others to distribute, remix, adapt, build upon this work non-commercially, and license their derivative works on different terms, provided the original work is properly cited, appropriate credit is given, any changes made indicated, and the use is non-commercial. See: http://creativecommons.org/licenses/by-nc/4.0/.

\section{REFERENCES}

1. WHO. Suicide. 2018 http://www.who.int/en/news-room/fact-sheets/ detail/suicide (Accessed 28 Nov 2018).

2. World Health Organization. Global Health Observatory (GHO) data. $2018 \mathrm{https}: / /$ www.who.int/gho/mental health/suicide rates_crude/ en/ (Accessed 31 Jan 2019).

3. Centraal Bureau voor de Statistiek (CBS). 1917 zelfdodingen in 2017. 2018 https://www.cbs.nl/nl-nl/nieuws/2018/27/1-917zelfdodingen-in-2017 (Accessed 12 Sep 2018).

4. ten Have M, van Dorsselaer S, Tuithof M. et al. Nieuwe gegevens over suïcidaliteit in de bevolking: Resultaten van de 'Netherlands Mental Health Survey and Incidence Study-2' (NEMESIS-2). Utrecht: Trimbos Instituut. 2011.

5. Raue PJ, Brown EL, Meyers BS, et al. Does every allusion to possible suicide require the same response? J Fam Pract 2006;55:605-12.

6. Van Hemert AM, Kerkhof A, De Keijser J, et al. Multidisciplinaire richtlijn diagnostiek en behandeling van suïcidaal gedrag. Utrecht: De Tijdstroom, 2012.

7. Hegerl U, Althaus D, Schmidtke A, et al. The alliance against depression: 2-year evaluation of a community-based intervention to reduce suicidality. Psychol Med 2006;36:1225-33.

8. Gilissen R, De Beurs D, Mokkenstorm J, et al. Improving Suicide Prevention in Dutch Regions by Creating Local Suicide Prevention Action Networks (SUPRANET): a study protocol. Int J Environ Res Public Health 2017;14:349.

9. De Leo D, Draper BM, Snowdon J, et al. Contacts with health professionals before suicide: missed opportunities for prevention? Compr Psychiatry 2013;54:1117-23.

10. Luoma JB, Martin CE, Pearson JL. Contact with mental health and primary care providers before suicide: a review of the evidence. Am J Psychiatry 2002;159:909-16.

11. de Beurs DP, Hooiveld M, Kerkhof AJ, et al. Trends in suicidal behaviour in Dutch general practice 1983-2013: a retrospective observational study. BMJ Open 2016;6:e010868.

12. Saini $P$, Chantler K, Kapur N. General practitioners' perspectives on primary care consultations for suicidal patients. Health Soc Care Community 2016;24:260-9.

13. Leavey G, Rosato M, Galway K, et al. Patterns and predictors of help-seeking contacts with health services and general practitioner detection of suicidality prior to suicide: a cohort analysis of suicides occurring over a two-year period. BMC Psychiatry 2016;16:120.

14. Pearson A, Saini P, Da Cruz D, et al. Primary care contact prior to suicide in individuals with mental illness. $\mathrm{Br} J$ Gen Pract 2009;59:825-32.

15. Houston K, Haw C, Townsend E, et al. General practitioner contacts with patients before and after deliberate self harm. Br J Gen Pract 2003;53:365-70.

16. Huisman A, Robben PB, Kerkhof AJ. Mental health reforms in Europe: further evaluation of the Dutch supervision system for suicides of mental health care users. Psychiatr Serv 2013;64:10-12.
17. Schulberg HC, Bruce ML, Lee PW, et al. Preventing suicide in primary care patients: the primary care physician's role. Gen Hosp Psychiatry 2004;26:337-45.

18. Gonda X, Fountoulakis KN, Kaprinis G, et al. Prediction and prevention of suicide in patients with unipolar depression and anxiety. Ann Gen Psychiatry 2007;6:23.

19. Mann JJ, Apter A, Bertolote J, et al. Suicide prevention strategies: a systematic review. J. Am. Med. Assoc 2005;294:2064-74.

20. Marquet RL, Bartelds Al, Kerkhof AJ, et al. The epidemiology of suicide and attempted suicide in Dutch General Practice 1983-2003. BMC Fam Pract 2005;6:45.

21. Wells KB, Schoenbaum M, Unützer J, et al. Quality of care for primary care patients with depression in managed care. Arch Fam Med 1999;8:529-36.

22. Bernert RA, Hom MA, Roberts LW. A review of multidisciplinary clinical practice guidelines in suicide prevention: toward an emerging standard in suicide risk assessment and management, training and practice. Acad Psychiatry 2014;38:585-92.

23. Ellis PM, Hickie IB, Smith DAR. Summary of guideline for the treatment of depression. Australasian Psychiatry 2003;11:34-8.

24. National Institute for Health and Care Excellence (NICE). Depression in adults: recognition and management management. 2009.

25. Bocquier A, Pambrun E, Dumesnil H, et al. Physicians characteristics associated with exploring suicide risk among patients with depression: a French panel survey of general practitioners. PLoS One 2013;8:e80797.

26. Bajaj P, Borreani E, Ghosh P, et al. Screening for suicidal thoughts in primary care: the views of patients and general practitioners. Ment Health Fam Med 2008;5:229-35.

27. Feldman MD, Franks P, Duberstein PR, et al. Let's not talk about it: suicide inquiry in primary care. Ann Fam Med 2007;5:412-8.

28. Verger P, Brabis PA, Kovess V, et al. Determinants of early identification of suicidal ideation in patients treated with antidepressants or anxiolytics in general practice: a multilevel analysis. J Affect Disord 2007;99:253-7.

29. Van Weel-Baumgarten $E$, Van Gelderen $M$, Grundmeijer $\mathrm{H}$, et al. NHG-Standaard Depressie (tweede herziening). 2012 https://www. nhg.org/standaarden/volledig/nhg-standaard-depressie-tweedeherziening (Accessed 23 Jul 2018).

30. van Hemert AM, de Kruif M. Dalende incidentie van zelfdoding en veranderende methoden. Ned Tijdschift voor Geneeskd 2009:153:1-6.

31. Donker GA. Nivel Zorgregistraties eerste lijn - Peilstations 2017. Utrecht 2018.

32. Bates D, Mächler M, Bolker B, et al. Fitting Linear Mixed-Effects Models Using Ime4. J Stat Softw 2015;67:1-48.

33. Lüdecke D. sjstats: statistical functions for regression models. sjstats Collect. Conv. Funct. Common Stat. Comput. 2018.

34. Beck AT, Kovacs M, Weissman A. Assessment of suicidal intention: the Scale for Suicide Ideation. J Consult Clin Psychol 1979;47:343-52.

35. O'Connor RC, Nock MK. The psychology of suicidal behaviour. Lancet Psychiatry 2014;1:73-85.

36. Core Team R. R: A language and environment for statistical computing. R Found. Stat Comput 2017 https://www.r-project.org/ (Accessed 29 Jan 2019).

37. DeCou CR, Schumann ME. On the latrogenic risk of assessing suicidality: a meta-analysis. Suicide Life Threat Behav 2018;48.

38. Smith P, Poindexter E, Cukrowicz K. The effect of participating in suicide research: does participating in a research protocol on suicide and psychiatric symptoms increase suicide ideation and attempts? Suicide and Life-Threatening Behavior 2010;40:535-43.

39. Vannoy SD, Robins LS. Suicide-related discussions with depressed primary care patients in the USA: gender and quality gaps. A mixed methods analysis. BMJ Open 2011;1:e000198.

40. Almeida OP, Pirkis J, Kerse N, et al. A randomized trial to reduce the prevalence of depression and self-harm behavior in older primary care patients. Ann Fam Med 2012;10:347-56.

41. Rutz W, von Knorring L, Pihlgren $\mathrm{H}$, et al. Prevention of male suicides: lessons from Gotland study. Lancet 1995;345:524.

42. Kessler RC, Borges G, Walters EE. Prevalence of and risk factors for lifetime suicide attempts in the National Comorbidity Survey. Arch Gen Psychiatry 1999;56:617-26.

43. Joling KJ, van Marwijk HW, Piek E, et al. Do GPs' medical records demonstrate a good recognition of depression? A new perspective on case extraction. J Affect Disord 2011;133:522-7. 